\title{
SIGNIFICADO DA EXPERIÊNCIA DE NÃO AMAMENTAR RELACIONADO ÀS INTERCORRÊNCIAS MAMÁRIAS
}

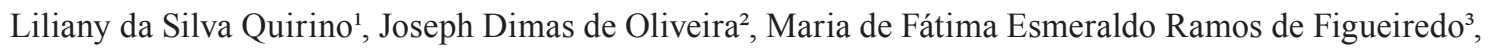
Glauberto da Silva Quirino ${ }^{4}$

\begin{abstract}
RESUMO: Objetivou-se relatar a vivência de mulheres na prática do aleitamento materno, descrever os sentimentos vivenciados pelas mães que não amamentaram e apreender o significado de não amamentar. Estudo descritivo, com abordagem qualitativa, realizado em Equipes Estratégia Saúde da Família, de Juazeiro do Norte-Ceará, com a participação de cinco mulheres que não estavam amamentando devido a intercorrências mamárias. Para a coleta de dados utilizou-se formulário de entrevista semiestruturada com análise temática de conteúdo; emergindo as categorias Vivência das mulheres na prática de aleitamento e Sentimentos vivenciados pelas mulheres. Os sentimentos atribuídos pelas participantes e o significado de não amamentar foram: tristeza, impotência, dor, alívio da obrigação, sossego. Considera-se que a amamentação é um processo contínuo de adaptação, ensino e aprendizagem e fortemente influenciado por fatores sociopsicoculturais, ideológicos e pessoais, e isso exige dos profissionais de saúde entendimento e capacitação para o tema.
\end{abstract}

PALAVRAS-CHAVE: Aleitamento materno; Desmame; Lactente; Enfermagem.

\section{THE MEANING OF THE EXPERIENCE OF NOT BREAST-FEEDING RELATED TO BREAST ISSUES}

\begin{abstract}
The objective of this study was to relate the experience of women in the practice of maternal breastfeeding, to describe the feelings experienced by those who do not breastfeed their babies, and study the meaning of not breastfeeding. The study is descriptive with a qualitative approach, and was carried out among Family Health teams in Juazeiro in North Ceará, with the participation of five women who were not breastfeeding due to breast issues. A questionnaire and semi-structured interview using thematic content analysis were used to collect data. Three categories emerged: The experience of women in the practice of breastfeeding and Feelings experienced by the women. The feelings noted by the participants and their meanings in not breast-feeding were sadness, impotence, pain, relief from obligation, and calming. It is considered that breastfeeding is a process of adaptation, teaching and learning and that it is strongly influenced by ideological, personal and socio-psycho-cultural factors: and that this demands of the health care professional both understanding and situation-specific training.
\end{abstract}

KEYWORDS: Breast-feeding; Weaning; Breast-feeding child; Nursing.

\section{SIGNIFICADO DE LA EXPERIENCIA DE NO AMAMANTAR RELACIONADA A LAS PROBLEMAS MAMARIOS}

RESUMEN: El objetivo del estudio fue relatar la vivencia de mujeres en la práctica del amamantamiento, describir los sentimientos vividos por las madres que no amamantaron y aprehender el significado del no amamantar. Estudio descriptivo, con abordaje cualitativo, realizado en Equipos de Salud de la Familia, de Juazeiro do Norte-Ceará, con la participación de cinco mujeres que no amamantaron por problemas mamarios. Para recoger los datos, fueron utilizados formulario y entrevista semiestructurada con análisis temático de contenido; surgiendo las categorías Vivencia de las mujeres en la práctica de amamantamiento y Sentimientos vividos por las mujeres. Los sentimientos relacionados por las participantes y el significado de no amamantar fueron: tristeza, impotencia, dolor, alivio de la obligación, sosiego. Se considera que el amamantamiento es un proceso continuo de adaptación, enseñanza y aprendizaje y fuertemente influenciado por factores sociopsico-culturales, ideológicos y persoales, y eso exige de los profesionales de salud entendimiento y capacitación para el tema.

PALABRAS-CLAVE: Amamantamiento materno; Desmame; Lactente; Enfermería.

\footnotetext{
${ }^{1}$ Enfermeira. Especializanda em Assistência e Gestão em Saúde da Família na Faculdade de Juazeiro do Norte-CE.

${ }^{2}$ Enfermeiro. Mestre em Cuidados Clínicos em Saúde. Professor do Curso de Graduação em Enfermagem da Universidade Regional do Cariri-URCA. ${ }^{3}$ Enfermeira. Especialista em Enfermagem Obstétrica. Professora do Curso de Graduação em Enfermagem da URCA.

${ }^{4}$ Enfermeiro. Mestre em Bioprospecção Molecular. Doutorando em Educação em Ciências: Química da Vida e Saúde pela Universidade Federal de Santa Maria-RS. Professor do Curso de Graduação em Enfermagem da URCA. Membro do Grupo de Pesquisa em Saúde Coletiva-GRUPESC.
} 


\section{INTRODUÇÃO}

O aleitamento materno é tido como um comportamento social universal das mulheres. Amamentar significa não somente um ato de amor, carinho, proteção, mas também um desafio. O aleitamento, apesar de ser um ato biológico, é histórico, sociocultural e psicologicamente influenciado ${ }^{(1)}$. Porém, os discursos favoráveis à amamentação tendem a evidenciar a visão romântica, omitindo possíveis problemas que possam ocorrer ${ }^{(2)}$.

A amamentação é um processo que parece simples e singularmente fisiológico, no entanto, para seja efetivo, é preciso um conjunto de condições interacionais no contexto em que o binômio mãe/filho está inserido. Para muitas mulheres, amamentar não é tão fácil como parece $\operatorname{ser}^{(3)}$.

A prática do aleitar é uma experiência que envolve uma gama de fatores maternos e outros que envolvem o recém-nascido. Dessa forma, o aleitamento materno não depende exclusivamente da decisão prévia de amamentar ou não, nem dos conhecimentos prévios da mulher sobre a técnica de amamentar ${ }^{(4)}$.

O leite humano, do ponto de vista nutricional, é o mais nutritivo e adequado alimento para a criança até os seis primeiros meses de vida, por ser rico em vitaminas, proteínas, sais minerais, água, carboidratos e gordura, que constituem-se em substâncias fundamentais para o crescimento e desenvolvimento infantil. Este alimento também contribui para a diminuição da mortalidade infantil, casos de diarreia, infecção do trato respiratório, otites e alergias, de risco de hipertensão, da dislipidemia e de diabetes, de chance de obesidade, tendo efeito positivo no desenvolvimento bucal, cognitivo e emocional, proteção da mãe contra o câncer de mama, além de atuar como método anticoncepcional, reduzir custos financeiros e promover maior vínculo afetivo entre mãe/bebê $\hat{e}^{(5)}$.

Apesar de serem amplamente difundidos os benefícios do aleitamento materno, em pesquisa realizada sobre sua prevalência nas capitais do Brasil, revelou-se que apenas $83,3 \%$ das crianças eram amamentadas no seu primeiro mês de vida, decrescendo para $72,5 \%$ aos 120 dias e para $68,6 \%$ aos 180 dias $^{(6)}$.

Esses dados denotam uma adesão ineficiente das mulheres à prática da amamentação que parece estar fortemente marcada por fatores que podem interferir e influir negativamente nesse processo, dentre os quais podemos listar alguns como: insuficiente conhecimento da população em geral, dos profissionais de saúde e dos gestores; práticas inadequadas nos serviços de saúde; práticas culturais e crenças; atuação materna extradomicílio; e intercorrências mamárias ${ }^{(7)}$.
Entre as dificuldades enfrentadas pela mulher nutriz situam-se as intercorrências mamárias, as quais podem influenciar e ser determinantes na decisão de continuar, ou não, a amamentação. Tais intercorrências têm início especialmente nos primeiros dias após o parto, em média entre o primeiro e o décimo quinto dia, quando o ritmo das mamadas ainda se apresenta instável. Por isso, os primeiros quinze dias pós-parto são decisivos para a mulher com relação ao aleitamento ${ }^{(8)}$.

As principais intercorrências mamárias relacionadas à lactação são: mamilo plano (semiprotuso), ingurgitamento mamário, fissura mamilar, mastite puerperal, bloqueio de ducto e abscesso mamário ${ }^{(8)}$.

Diante das dificuldades e desconfortos iniciais que podem ocorrer durante a amamentação, as mulheres podem não conseguir seguir em frente no processo, sendo isto considerado uma das principais causas do desmame precoce ${ }^{(9)}$.

Nesse sentido, ao contrário do que ocorre com todos os demais mamíferos, a mulher não amamenta como um ato instintivo, por isso ela deve aprender como realizar o aleitamento. Compete ao profissional de saúde que assiste a mulher, ainda no período prénatal, participar ativamente desse ensinamento ${ }^{(5)}$.

Desse modo, ao considerar que há um apelo discursivo sobre os benefícios da amamentação exclusiva; que a ação se constitui um ato de amor e de normalidade biológica e social e, que nem todas as mulheres conseguem amamentar, objetivamos relatar a vivência das mulheres na prática do aleitamento materno, além de descrever os sentimentos vivenciados pelas mulheres que não amamentaram devido às intercorrências mamárias e apreender o significado de não amamentar atribuído pelas mães.

Acreditamos que este estudo incentive a reflexão e discussão acerca da prática do aleitamento materno como uma realidade sociocultural, permeada pelas dificuldades enfrentadas pelas nutrizes, pelos sentimentos gerados pela influência discursiva sobre o ato e, portanto, sobre a prática assistencial como uma estratégia que minimiza os impactos gerados.

\section{METODOLOGIA}

Pesquisa de natureza descritiva, com abordagem qualitativa ${ }^{(10)}$, realizada no Município de Juazeiro do Norte, localizado no sul do Estado do Ceará e que conta com, aproximadamente, 249.829 habitantes $^{(11)}$, possui 61 Equipes de Saúde da Família (ESF), sete Núcleos de Apoio a Saúde da Família (NASF) e uma Unidade de Pronto Atendimento (UPA), há no município 62 
unidades básicas de saúde que abrigam, em geral, apenas uma equipe de saúde da família.

O estudo ocorreu entre janeiro e fevereiro de 2011, em quatro equipes de Saúde da Família da zona urbana e contou com a participação de cinco mulheres. As equipes foram selecionadas por conveniência; a escolha se deu pela facilidade de acesso para coleta de dados e por ser campo de estágio curricular do Curso de Graduação em Enfermagem da Universidade Regional do Cariri, o que facilitou o desenvolvimento técnico e operacional da pesquisa.

Esta pesquisa se realizou em dois momentos: identificação das mulheres que estavam cadastradas nas quatro equipes de saúde da família e que não mantinham a prática do aleitamento exclusivo, nessa fase obtemos seus endereços, através de consultas nos livros de registros de pré-natal; e, visitas domiciliares para verificação do preenchimento dos critérios de inclusão e composição das participantes do estudo, quando explicamos os objetivos da pesquisa e, ao concordarem em participar, assinaram o Termo de Consentimento Livre e Esclarecido (TCLE) e para aquelas menores de 18 anos foi solicitado que o responsável assinasse conjuntamente o TCLE.

As mulheres selecionadas no primeiro momento foram submetidas aos critérios de inclusão e apenas cinco se enquadravam neles: residir no local pesquisado; encontrar-se até o quarto mês pós-parto; que tivessem apresentando ou que apresentaram as seguintes intercorrências mamárias: mamilo plano (semiprotuso), pega inadequada, ingurgitamento mamário, trauma mamilar, mastite e abscesso mamário, e, por essa razão não conseguiram amamentar. As demais mulheres (nove), embora não praticassem o aleitamento exclusivo, o abandonaram por motivos não relacionados às intercorrências mamárias. Portanto, o número de participantes compreendeu a totalidade das mulheres que atendiam aos critérios de inclusão.

Foram utilizados um formulário que continha itens para caracterização sociodemográfica e obstétrica das mães e uma entrevista do tipo semiestruturada com perguntas abertas sobre a vivência prévia da amamentação e os sentimentos e significados da experiência de não amamentar. Um gravador de áudio foi usado para registrar os depoimentos e expressões de linguagem citadas pelos sujeitos, no intuito de transcrevê-los com mais fidedignidade.

Para organização, apresentação e análise dos dados, optamos pela análise do conteúdo, do tipo análise temática. Esse tipo de análise, operacionalmente, divi- de-se em três fases: pré-análise, exploração do material e tratamento dos resultados obtidos e interpretados ${ }^{(12)}$.

Após a realização das entrevistas, realizamos uma leitura exaustiva do material, revimos os objetivos e organizamos todo o material selecionado. Em seguida, transcrevemos todas as entrevistas. Posteriormente, organizamos um quadro de convergências e divergências, sendo utilizado o método colorimétrico, onde os depoimentos semelhantes recebiam marcação com cores iguais.

Posteriormente à construção do quadro mencionado, identificamos o núcleo central, depois agrupamos as ideias e identificamos os temas. Transcorrida essa etapa, elaboramos duas categorias, e a partir destas, procedemos à análise de cada tema ${ }^{(12)}$. Por fim, foi realizada a compreensão e interpretação dos dados à luz da literatura.

A pesquisa obedeceu a Resolução de n. 196/96, do Conselho Nacional de Saúde ${ }^{(13)}$. A decisão voluntária de desejar ou não participar da pesquisa foi respeitada, bem como foram garantidos os anonimatos das participantes e, para isso utilizamos pseudônimos inspirados em nomes populares de flores. Este estudo foi submetido ao Comitê de Ética em Pesquisa da Universidade Regional do Cariri, tendo sido aprovado pelo parecer de número 26/2010.

\section{RESULTADOS}

A faixa etária das participantes variou entre 16 e 29 anos, possuíam baixo nível de escolaridade e renda mensal entre um e dois salários mínimos e estavam vivenciando a maternidade pela primeira vez.

\section{Vivência das mulheres na prática de aleitamento}

Durante a entrevista, fizemos questionamentos com relação às dificuldades encontradas em amamentar, a orientações acerca do aleitamento materno durante o pré-natal e a procura de ajuda profissional diante das dificuldades existentes. Todas as mulheres referiram ter tido algum problema relacionado à mama, o que impossibilitou a amamentação; no entanto, relataram ter sido orientadas quanto à prática de aleitar.

Problemas como mamilos doloridos e fissurados, ingurgitamento mamário, abscesso, mamilo plano, dificuldades da pega adequada foram relatados durante as entrevistas:

Não tenho bico. Ele não pegou o peito. (Orquídea)

Foi difícil, meu seio feriu, ficou machucado, inchou, pedrou, doía muito. (Margarida) 
No início nenhuma [...], depois de mais ou menos uns cinco dias, os meus seios incharam muito, [...], depois nasceu um caroço, ai não aguentei a dar mais o peito, me deu até febre. (Tulipa)

As entrevistadas informaram que fizeram entre seis e oito consultas de pré-natal e que ao se deparar com as dificuldades durante a amamentação procuraram ajuda profissional, a fim de solucionar o problema:

O enfermeiro mandou eu fazer ordenha, tirar para poder não ficar tão pedrado, para não dar febre. (Margarida)

Fui atrás de ajuda sim. Tirava o leite para esvaziar um pouco, fazia compressa de água morna, massagem, tentei um monte de coisa, mas ficou muito pedrado. (Tulipa)

Apesar da maioria das entrevistadas ter procurado suporte assistencial e tentado continuar amamentando seus bebês, nenhuma delas logrou êxito na amamentação.

\section{Sentimentos vivenciados pelas mulheres}

\section{Subcategoria - Tristeza e impotência}

A amamentação, quando não acontece, pode levar a sentimentos de frustração na mulher:

Me senti mal, chorei, fiquei triste. (Margarida)

Tristeza grande! Porque eu queria dar o peito. (Sangue de Cristo)

Fiquei muito mal, muito triste, uma sensação de impotência. (Tulipa)

Observamos que essas mães desejavam amamentar, entretanto, com as dificuldades apresentadas, emergiram sentimentos negativos.

\section{Subcategoria - Alívio da obrigação}

O sentimento expresso pelas mulheres foi de alívio por se livrar da necessidade de aleitar:

Mulher, na verdade, sinceramente, não achei muito ruim não! (Orquídea)
Dei o peito porque disseram que era bom para o bebê. (Linda Maria)

Algumas mulheres atribuíram o significado de não amamentar como uma experiência de sossego e alívio da dor; o que para elas constituiu em uma prática dolorosa e estressante:

É, assim. Como eujá disse, é bom até porque o menino num fica ripuxando [sic] a gente e a gente fica mais sossegada. (Orquídea)

Muito não, dói demais. (Linda Maria)

\section{DISCUSSÃO}

Ser primípara é um dos principais fatores predisponentes para o insucesso da amamentação. O grau de escolaridade pode interferir na amamentação, pois, auxilia muito na decisão de continuar, ou não, a oferecer o peito, associado a melhor compreensão das orientações fornecidas. O baixo poder econômico pode estar relacionado à decisão de amamentar, pois as classes menos favorecidas são as que menos amamentam ${ }^{(14)}$.

A pouca experiência também pode se configurar como uma condição que poderá dificultar ou impossibilitar a amamentação. A insegurança materna, decorrente da pouca experiência, tanto pessoal quanto por observação de outras mulheres amamentando, é fator que influencia na decisão por essa prática. A amamentação é um processo diferente a cada experiência, e por isso precisa ser aprendido e reaprendido ${ }^{(1)}$.

Quando as mulheres se encontram frente às dificuldades que surgem durante a amamentação, estas podem trazer impacto significante no ato da mulher decidir se irá continuar, ou não, com esta prática.

As intercorrências mamárias evidenciam que muitos são os fatores para o desmame. $\mathrm{O}$ ato de amamentar, apesar de ser considerado biológico e natural na espécie humana, não é meramente instintivo, requerendo aprendizado, apoio, proteção e, acima de tudo, respeito à decisão das mães sobre o desejo de continuar amamentando, ou não, os seus filhos ${ }^{(15)}$.

Movimentos firmados nas ideologias em favor à amamentação e aos benefícios que o leite humano fornece para as crianças caracterizam-se por campanhas focalizadas na responsabilidade da mulher em amamentar, associando a amamentação ao amor materno, como se bastasse ser mãe para saber amamentar e vencer todos os obstáculos ${ }^{(2)}$. 
No entanto, as intercorrências mamárias mencionadas não são motivos para impossibilitar a amamentação, pois, dependem das orientações fornecidas, do apoio, do incentivo e encorajamento, dos ensinamentos de técnicas e das medidas profiláticas, durante o ciclo gravídico-puerperal, que podem diminuir ou evitar essas intercorrências ${ }^{(16)}$. Nesse sentido, a equipe de enfermagem acredita que sua atuação na promoção à saúde e assistência de qualidade são fundamentais para o enfrentamento desses problemas ${ }^{(17)}$.

A amamentação é permeada por conflitos e, do ponto de vista social, amamentar prazerosamente o filho é o perfil desejado e esperado de uma boa mãe ${ }^{(18)}$. Assim, quando a amamentação não acontece, a mulher tende a ter sentimentos negativos, pois, deve enfrentar posições difíceis a serem assumidas em uma sociedade em que amamentar o filho é comportamento tão esperado ${ }^{(19)}$.

Como se disse, tratam-se de situações delicadas, uma vez que as expressões 'não quer amamentar', 'não gosta' ou 'não tem paciência', ou 'é obrigada porque dizem que é bom para o bebê', não condizem com o perfil idealizado de mãe numa sociedade em que há grande apelo pela promoção do aleitamento materno ${ }^{(19)}$.

A amamentação limita e interfere significativamente na vida da mulher, podendo desencadear sentimentos de impaciência, irritação e até raiva ${ }^{(20)}$. Logo, considera-se que a possibilidade de amamentar nem sempre se concretiza como uma experiência positiva, pois para algumas mulheres, muitas vezes, torna-se um fardo, uma obrigação, pela expectativa da sociedade e também pelos inúmeros papeis que elas têm que desempenhar como mãe e mulher.

Dessa forma, o ato de amamentar, antes de ser concebido, é vivenciado ${ }^{(20)}$. E, quando a amamentação idealizada não acontece, o sonho se transforma em incertezas na vida da mulher que não conseguiu concretizar o sonho de poder amamentar o bebê no peito.

Acreditamos não ser fácil e nem simples para as mulheres expor seus sentimentos e suas dificuldades relativas à amamentação. A amamentação pode parecer natural, no entanto, demonstra-se dificultada, baseada no aprendizado, na experiência, na observação e nos exemplos vivenciados por outras mães e, portanto, modifica-se de acordo com a realidade sociocultural.

\section{CONSIDERAÇÕES FINAIS}

As mulheres que foram entrevistadas perceberam a experiência de amamentar como sofrimento, seja por que desejavam amamentar, mas não conseguiram executá-la, seja porque se sentiam obrigadas.
Todas as intercorrências relatadas pelas mulheres são típicas do processo de amamentar, no entanto, elas podem ser causadoras do desmame precoce. Portanto, cabe ao profissional que assiste a essas mulheres, durante o ciclo gravídico-puerperal, transmitir orientações adequadas, ouví-las e conhecer as informações que elas detêm acerca do aleitamento materno, a fim de detectar e corrigir precocemente possíveis dificuldades que venham favorecer o desmame precoce.

Perante os resultados obtidos, afigura-se importante analisar as intervenções dos profissionais de saúde envolvidos, quanto ao seu papel de educadores e promotores da saúde, valendo a pena ressaltar que as abordagens precisam abandonar o caráter de apenas enaltecer as vantagens bioquímicas e fisiológicas do leite materno para a saúde da criança, mas também incorporar o entendimento do significado da maternidade e da corporeidade no cotidiano da mulher.

É preciso desenvolver estratégias que reconheçam a posição da mulher, de modo a valorizá-las como sujeitos de direito e donas do seu corpo, evitando reproduzir o discurso da culpabilidade e da responsabilização quando a amamentação não acontece.

Essa diversidade de sentimentos associados a uma mesma experiência, alerta para a importância de compreendere integrar o conceito de amamentação como uma experiência complexa, dinâmica, fortemente influenciada por inúmeros fatores sociopsicoculturais, ideológicos e pessoais.

Enfim, toda experiência deve ser reconhecida em seu valor, considerando que, de cada vivência, emergem significados singulares que merecem ser ouvidos, estabelecendo uma relação na qual a mulher se sinta livre para demonstrar suas percepções. Enfim, os saberes dos profissionais e das mulheres devem atuar em conjunto, na perspectiva de que a prática da amamentação possa ocorrer de forma não persuasiva, não mecânica, mas prazerosa e, portanto, tendo possibilidades de ser mantida por mais tempo.

Constatamos que a amamentação não deve ser vista como uma tarefa fácil, natural ou intuitiva, e sim uma experiência complexa que envolve uma gama de fatores. E foi exatamente assim que as mulheres enfrentaram o processo de amamentar, como uma experiência complexa.

\section{REFERÊNCIAS}

1. Araújo RMA, Almeida JAG. Aleitamento materno: o desafio de compreender a vivência. Rev Nutr. 2007;20(4):431-8. 
2. Monteiro JCS, Gomes FA, Nakano AMS. Amamentação e o seio feminino: uma análise sob a ótica da sexualidade e dos direitos reprodutivos. Texto \& Contexto Enferm. 2006;15(1):146-50.

3. Sales CM, Seixas SC. Causas de desmame precoce no Brasil. Cogitare Enferm. 2008;13(3):443-7.

4. Andrade MP, Oliveira MIV, Bezerra Filho JG, Bezerra MGA, Almeida LS, Veras MAC. Desmame precoce: vivência entre mães atendidas em unidade básica de saúde em Fortaleza-Ceará. Rev Rene. 2009;10(1):104-13.

5. Ministério da Saúde (BR). Secretaria de Atenção à Saúde. Saúde da criança: nutrição infantil, aleitamento materno e alimentação complementar. Manual técnico. Brasília: Ministério da Saúde; 2009.

6. Sena MCF, Silva EF, Pereira MG. Prevalência do aleitamento materno nas capitais brasileiras. Rev Assoc Med Bras. 2007;53(6):520-4.

7. Araújo OD, Cunha AL, Lustosa LR, Nery IS, Mendonça RCM, Campelo SMA. Aleitamento materno: fatores que levam ao desmame precoce. Rev Bras Enferm. 2008;61(4):488-92.

8. Castro KF, Souto CMRM, Rigão TVC, Garcia TR, Bustorff LACV, Braga VAB. Intercorrências mamárias relacionadas à lactação: estudo envolvendo puérperas de uma maternidade pública de João Pessoa, PB. O Mundo da Saúde. 2009;33(4):433-9.

9. Azevedo DS, Reis ACS, Freitas LV, Costa PB, Pinheiro PNC, Damasceno AKC. Conhecimento de primíparas sobre os benefícios do aleitamento materno. Rev Rene. 2010;11(2):53-62.

10. Gil AC. Métodos e técnicas de pesquisa social. $6^{\mathrm{a}}$ ed. São Paulo: Atlas; 2009.

11. Instituto Brasileiro de Geografia e Estatística (IBGE). [Internet]. 2009 [citado 5 jun 2010]. Disponível: http:// dialogospoliticos.wordpress.com/2009/08/15/ibgeestimativa-populacional-dos-municipios-do-cearaem-2009/.

12. Minayo MCS. O desafio do conhecimento: pesquisa qualitativa em saúde. 11ª ed. São Paulo: Hucitec; 2008.

13. Ministério da Saúde (BR). Conselho Nacional de Saúde. Diretrizes e normas regulamentadoras de pesquisas envolvendo seres humanos. Resolução n. 196, de 10 de outubro de 1996. Brasília; 1996.
14. Vitolo MR, Benetti SPC, Bortolini GA, Graeff A, Drachler ML. Depressão e suas implicações no aleitamento materno. Rev Psiquiatr. 2007;29(1):28-34.

15. Chaves RG, Lamounier JA, César CC. Fatores associados com a duração do aleitamento materno. J Pediatr. 2007;83(3):241-6.

16. Fujimori E, Nakamura E, Gomes MM, Jesus LA, Rezende MA. Aspectos relacionados ao estabelecimento e à manutenção do aleitamento materno exclusivo na perspectiva de mulheres atendidas em uma unidade básica de saúde. Interface - Comunicação, Saúde, Educação. 2010;14(33):315-27.

17. Souza Filho MD, Gonçalves Neto PNT, Martins MCC. Avaliação dos problemas relacionados ao aleitamento materno a partir do olhar da enfermagem. Cogitare Enferm. 2011;16(1):70-5.

18. Takushi SAM, Tanaka ACA, Gallo PR, Machado MAMP. Motivação de gestantes para o aleitamento materno. Rev Nutr. 2008;21(5):491-502.

19. Silva MBC, Moura MEB, Silva AO. Desmame precoce: representações sociais de mães. Rev Eletr Enferm. [Internet] 2007;9(1) [acesso em 18 jun 2011]. Disponível: http://www.fen.ufg.br/revista/v9/n1/v9n1a03.htm

20. Osório CM, Queiroz ABA. Representações sociais de mulheres sobre a amamentação: teste de associação livre de ideias acerca da interrupção precoce do aleitamento materno. Esc Anna Nery. 2007;11(2):261-7. 